\title{
The Australian Paradox: A Substantial Decline in Sugars Intake over the Same Timeframe that Overweight and Obesity Have Increased
}

\author{
Alan W. Barclay ${ }^{1}$ and Jennie Brand-Miller ${ }^{2}$ * \\ 1 Australian Diabetes Council, 26 Arundel Street, Glebe, NSW 2037, Australia; \\ E-Mail: awbarclay@optusnet.com.au \\ 2 School of Molecular Bioscience and Boden Institute of Obesity, Nutrition and Exercise, \\ University of Sydney, NSW 2006, Australia \\ * Author to whom correspondence should be addressed; E-Mail: j.brandmiller@mmb.usyd.edu.au; \\ Tel.: +61-2-9351-3759; Fax: +61-2-9351-6022.
}

Received: 4 March 2011; in revised form: 14 April 2011 / Accepted: 19 April 2011 /

Published: 20 April 2011

\begin{abstract}
Ecological research from the USA has demonstrated a positive relationship between sugars consumption and prevalence of obesity; however, the relationship in other nations is not well described. The aim of this study was to analyze the trends in obesity and sugar consumption in Australia over the past 30 years and to compare and contrast obesity trends and sugar consumption patterns in Australia with the UK and USA. Data on consumption of sugar in Australia, the UK and USA were obtained from the Food and Agriculture Organization for the years 1980-2003. The prevalence of obesity has increased 3 fold in Australians since 1980. In Australia, the UK and USA, per capita consumption of refined sucrose decreased by $23 \%, 10 \%$ and $20 \%$ respectively from 1980 to 2003 . When all sources of nutritive sweeteners, including high fructose corn syrups, were considered, per capita consumption decreased in Australia $(-16 \%)$ and the UK $(-5 \%)$, but increased in the USA $(+23 \%)$. In Australia, there was a reduction in sales of nutritively sweetened beverages by 64 million liters from 2002 to 2006 and a reduction in percentage of children consuming sugar-sweetened beverages between 1995 and 2007. The findings confirm an "Australian Paradox" - a substantial decline in refined sugars intake over the same timeframe that obesity has increased. The implication is that efforts to reduce sugar intake may reduce consumption but may not reduce the prevalence of obesity.
\end{abstract}


Keywords: sugars; sucrose; obesity; epidemiology; Australia

\section{Introduction}

The prevalence of overweight/obesity continues to rise around the globe, in both developed and developing nations. The World Health Organization estimates that there are currently more than 700 million overweight adults, and at least 300 million obese adults [1]. The health consequences of overweight/obesity are well documented, and include increased risk of cardiovascular disease, cancer (endometrial, breast, and colon), type 2 diabetes, respiratory problems and osteoarthritis [2]. The economic costs of overweight/obesity are as equally grave as the health consequences, but not as well described. However, in several developed countries, obesity has been estimated to account for $2-7 \%$ of the total health care costs [3].

The most recent population health surveys in Australia determined that in 2007-2008, 62\% of Australia's 15 million adults [4] and 23\% of Australia's 5 million children [5] were either overweight or obese. The direct financial cost of obesity was estimated to be AUD $\$ 8.283$ billion in Australia in 2008. In addition to this, the cost of lost wellbeing due to obesity was valued at AUD $\$ 49.9$ billion, bringing the total cost of obesity in Australia in 2008 to AUD\$58.2 billion [6].

While the cause of this pandemic of overweight/obesity is complex, multi-factorial, and likely to vary from region-to-region, researchers continue to look for common environmental factors to help explain the phenomenon. Increasing consumption of sugars [7], and in particular sugar-sweetened beverages [8], has been identified as a plausible etiological factor in the United States. Little is known about the relationship between sugars consumption and obesity in other nations, however.

The aim of this study was to examine in detail trends in obesity in Australia, and to analyze concurrent trends in sugars and sugar-sweetened beverage consumption, and to compare these to those in the United Kingdom (UK) and the United States of America (USA).

\section{Methods}

\subsection{Literature Search}

A systematic literature review was undertaken to obtain sources of Australian sugar intake data. Key words used in the search included: sugars, sucrose, dietary carbohydrate, consumption, intake, sugar-sweetened beverages, sweeteners, refined sugar, obesity, adiposity, body weight, body mass index (BMI) with Australia. The term "blood glucose" was excluded in the search strategy. The databases searched were MEDLINE, Cinahl, Embase and the Cochrane library. Full papers were retrieved if they included a healthy population as the sub-group and were relevant in the Australian context and published within the last 30 years (since 1980).

In addition to the peer-reviewed literature, publications and data issued by government, academia and industry were also explored. The websites of the World Health Organization (WHO) [9], Food and Agriculture Organization (FAO) of the United Nations [9], Australian Bureau of Statistics [10], Australian Food and Grocery Council [11], Australian Retailers Association [12], Commonwealth 
Scientific and Industrial Research Organization (CSIRO) [13] and the Australian Government [14] were searched for relevant information. The Australian food industry including the Australian Beverage Council (Ltd.) [15], CSR (Ltd.) [16], Coles [17] and Woolworths [18] supermarkets were also contacted for relevant data.

For this analysis, water based beverages were categorized as nutritively sweetened or non-nutritively sweetened. Nutritively sweetened beverages included all sugar-sweetened (cane or fruit sugar) beverages such as soft drinks, sports drinks, iced tea drinks and flavored waters, but Non-nutritively sweetened beverages were defined as plain still/mineral waters or beverages sweetened with non-nutritive sweeteners.

\subsection{Prevalence of Obesity}

Obesity statistics describing the percentage of obesity in the study population using BMI $\geq 30 \mathrm{~kg} / \mathrm{m}^{2}$ in adults and a BMI greater than or equal to the 95th percentile, using age and sex dependent reference values in children, were obtained.

Annual trends in obesity prevalence were obtained for Australia, the UK and the USA from a variety of sources. In Australia, data were sourced from the Australian Institute of Health and Welfare Risk Factor Data [18] store which was based on an analysis of the 1980, 1983 and 1989 Risk Factor Prevalence Surveys [19]; the 1995 National Nutrition Survey [20]; the 1999-2000 Australian Diabetes, Obesity and Lifestyle study [21]; the Australian Bureau of Statistics National Health Survey's of 2004-2005 [22] and 2007-2008 [4] and the 2007 Australian National Children's Nutrition and Physical Activity Survey [5]. In the UK, data were obtained from the Health Survey for England 2007 Latest Trends [23] and for the USA, from the National Health and Nutrition Examination Survey data (NHANES) [24].

\subsection{Sugars Consumption}

Data on annual apparent consumption of sugar were obtained for Australia, the UK and the USA from the FAO [25]. Average population sugar, sugary foods and beverages intake estimates were obtained from the 2007 Australian National Children's Nutrition and Physical Activity Survey [5,26] and food and nutrient intakes from the 1983, 1985 and 1995 National Nutrition Surveys [19]. Australian Bureau of Statistics population estimates [27] were used to obtain data for total per capita beverage sales.

Dr. Gina Levy [28] provided supplementary water-based beverage volume sales data for the years 2005 and 2006. The Australian Beverage Council Ltd. [15] representing major water-based beverage companies such as Coca-Cola Amatil Australia, Pepsico Australia, Cadbury Schweppes Australia and Unilever Australasia, provided volume sales data for the 10 year period from 1994 to 2004. This sales data was formerly from AC Nielsen Scan Track Data [29]. 


\section{Results}

\subsection{Obesity Prevalence}

Obesity rates increased in Australia [18], the UK [23] and the USA [24], for adults, adolescents and children (Figure 1).

Figure 1. Prevalence of obesity (\%) in (A) Australian adults, (B) Australian children, (C) adults in the United Kingdom, (D) children in the United Kingdom and (E) American adults $(\mathbf{F})$ and children [18,23,24].

\section{Adults}

(A)

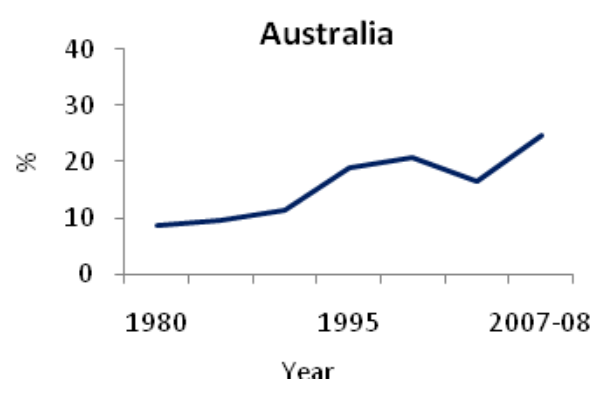

(C)

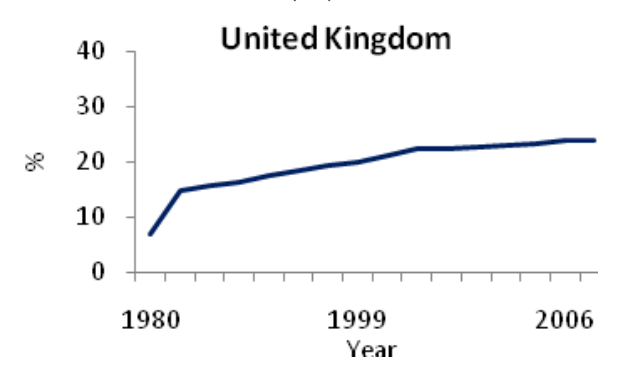

(E)

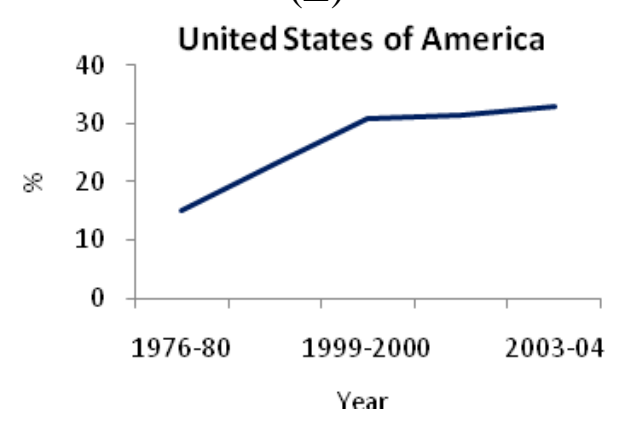

\section{Children}

(B)

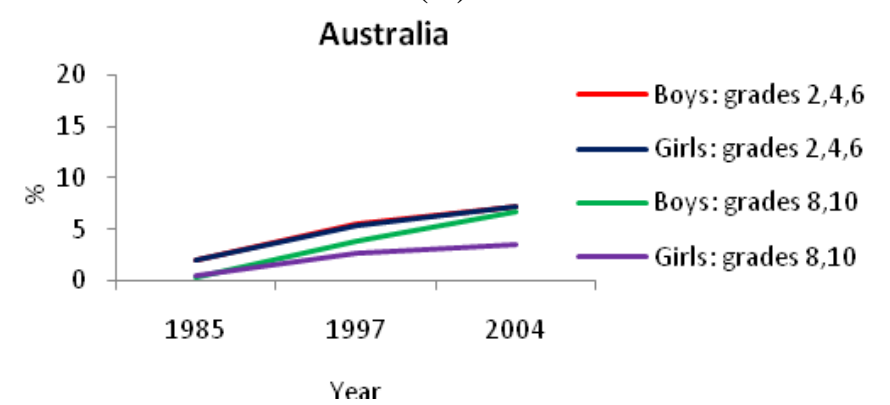

(D)

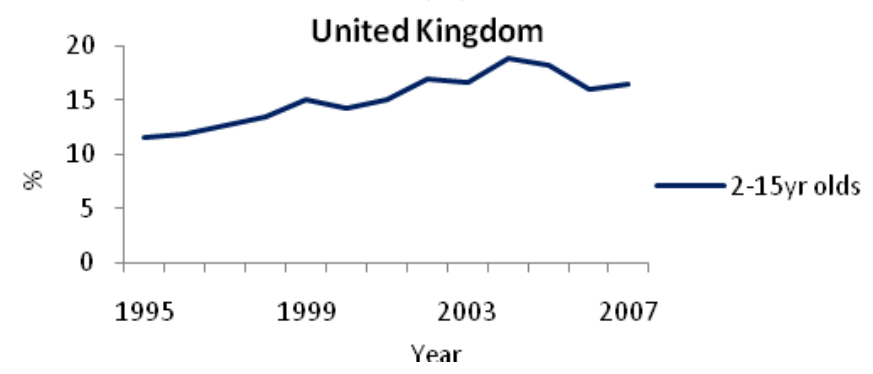

(F)

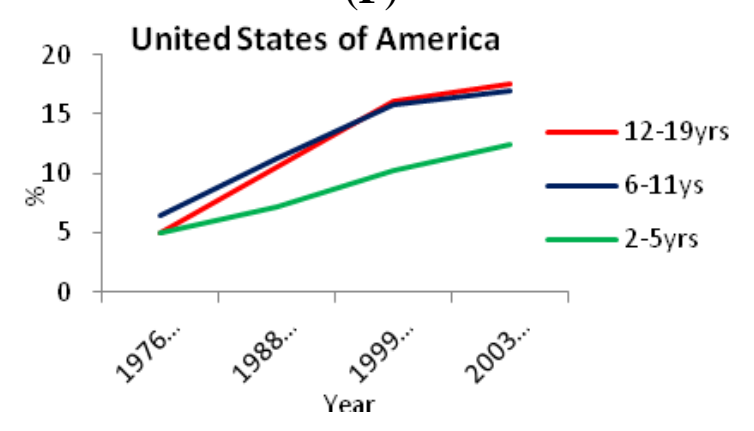

\subsection{Apparent Consumption of Sugar}

Figure 2 shows the refined and added sugars consumption (kg/capita/year) for Australia, the UK and the USA from 1980 to 2003 [25]. Over the period 1980-2003 in Australia, consumption of total nutritive sweeteners fell $16 \%$ (9 kg, or $25 \mathrm{~g}$ per day), refined sucrose consumption dropped $23 \%$ $(11 \mathrm{~kg}$ ) and consumption of other sweeteners (glucose, dextrose, fructose, lactose, isoglucose, maltose, maple sugar or similar) increased from a small baseline to $3 \mathrm{~kg}$ per capita ( $8 \mathrm{~g}$ per day). Over this same 
period in the UK, consumption of total nutritive sweeteners fell $5 \%$ (2 $\mathrm{kg}$, or $6 \mathrm{~g}$ per day), refined sucrose consumption dropped $10 \%(4 \mathrm{~kg})$ and consumption of other sweeteners increased to $1 \mathrm{~kg}$ per capita from zero consumption in 1980. In the USA, from 1980 to 2003, consumption of total nutritive sweeteners increased 23\% (13 kg = $37 \mathrm{~g}$ per day), refined sucrose consumption dropped $20 \%$ ( $7 \mathrm{~kg}$ ) while consumption of other sweeteners (primarily high fructose corn syrups in the USA) increased $138 \%(22 \mathrm{~kg})$. In all three countries, the consumption of refined sucrose showed a downward trend [25].

Figure 2. Intake of added sugars (kg/capita/year) in (A) Australia, (B) the United Kingdom and $(\mathbf{C})$ the United States of America [25].

(A)

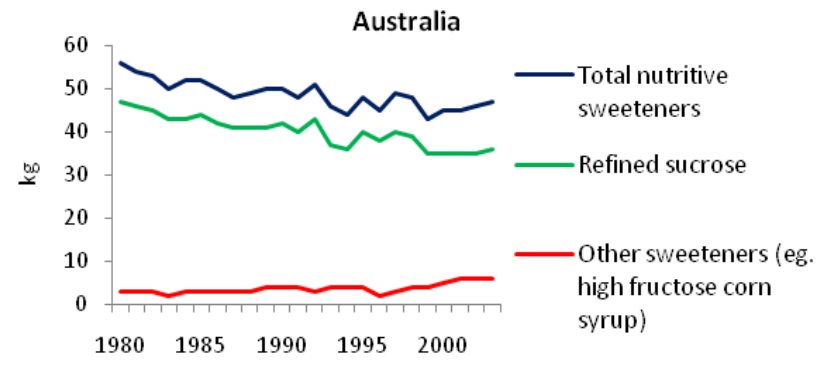

(B)

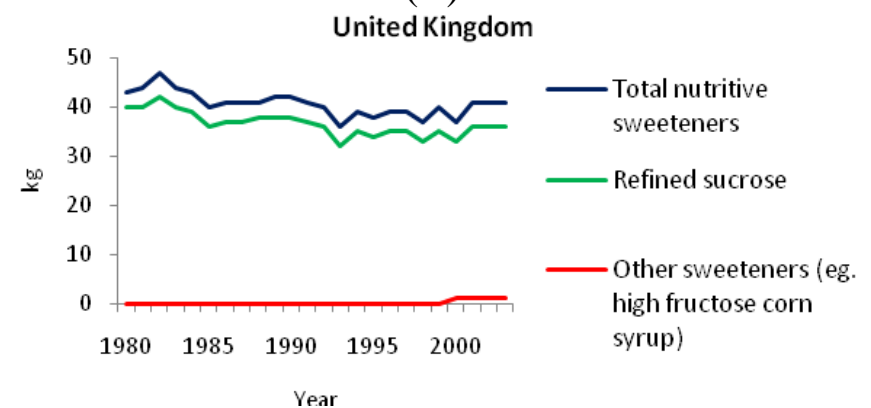

(C)

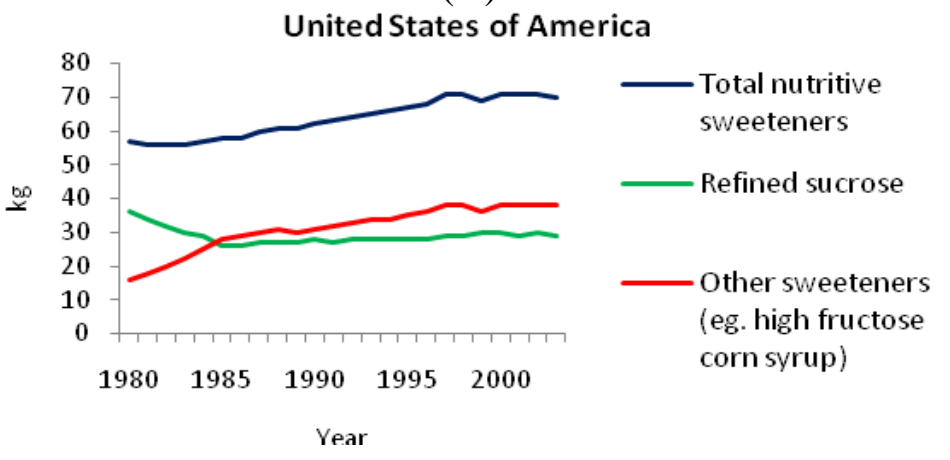

Figure 3 shows an historical comparison of the $24 \mathrm{~h}$ sugars intakes from various sources for Australian adults in 1983 and 1995 (most recent data available) [19]. For men, intake of total sugars (added and naturally occurring sugars in fruit, fruit juices, etc.) increased by $12 \%$ to $129 \mathrm{~g}$ from 1983 to 1995 . For women, intake of total sugars increased by $6 \%$ to $94 \mathrm{~g}$ over this period. With regard to confectionery mean $24 \mathrm{~h}$ intake increased from $7 \mathrm{~g}$ to $9 \mathrm{~g}$ for both men and women from 1983 to 1995 . Although the intake of confectionery showed an upward trend, absolute intake was small ( $<10 \mathrm{~g})$ in comparison with the other sources. Intake of sugary products (e.g., cakes, cookies) decreased from $28 \mathrm{~g}$ to $22 \mathrm{~g}$ and $18 \mathrm{~g}$ to $15 \mathrm{~g}$ for both men and women respectively. For men, intake of all non-alcoholic beverages (including fruit and vegetable juices, cordials, tea and coffee, mineral waters, electrolyte drinks, sugar and non-nutritively sweetened soft drinks) increased by $15 \%$ to $1274 \mathrm{~g}$ from 1983 to 1995 . For women, intake of all non-alcoholic beverages (including non-nutritively sweetened varieties) increased by $9 \%$ to $1159 \mathrm{~g}$ over the same time period. 
Figure 3. $24 \mathrm{~h}$ mean intake (g) of total sugars, sugary products, confectionery and non-alcoholic beverages * by Australian adults (25-64 years) in 1983 and 1995 [19].

TOTALSUGARS (ADDED \& NATURALLY OCCURRING)

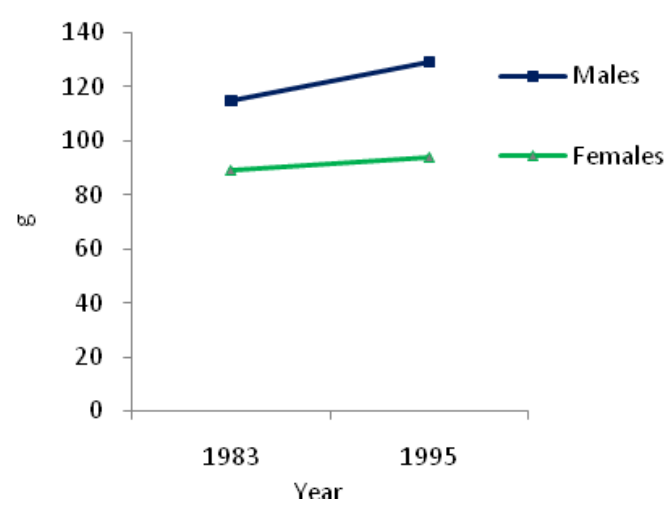

CONFECTIONERY

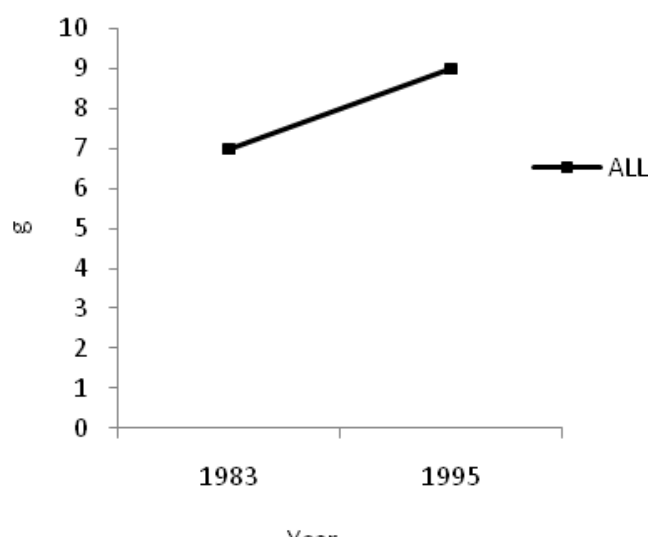

SUGARY PRODUCTS

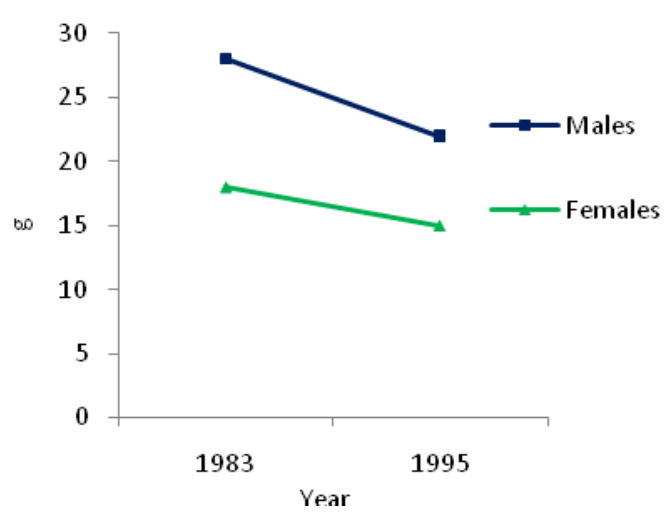

NON-ALCOHOLIC BEVERAGES

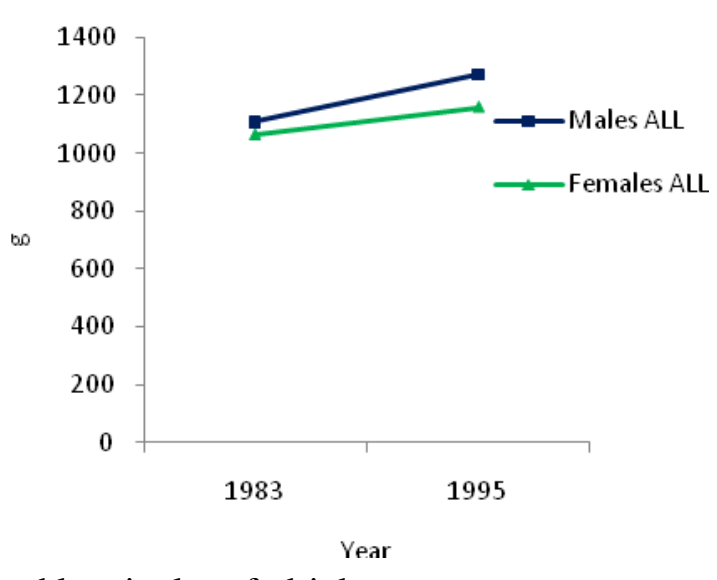

* Including coffee, tea and low joule soft drinks.

Figure 4 shows a comparison of the $24 \mathrm{~h}$ mean sugars intakes for children. For boys, intake of total sugars (added and naturally occurring) increased from $142 \mathrm{~g}$ in 1985 to $174 \mathrm{~g}$ in 1995 [19], but then declined to $154 \mathrm{~g}$ in 2007 [5]. Girls showed a similar pattern of intake of total sugars, with an increase from $115 \mathrm{~g}$ in 1985 to $137 \mathrm{~g}$ in 1995, then a fall to $125 \mathrm{~g}$ in 2007. In boys, intake of confectionery showed an increasing intake ( $16 \mathrm{~g}$ to $25 \mathrm{~g}$ to $28 \mathrm{~g}$ ) for the years 1985, 1995 and 2007 respectively. Girls showed a similar increasing intake ( $15 \mathrm{~g}$ to $21 \mathrm{~g}$ to $24 \mathrm{~g}$ ) across 1985, 1995 and 2007.

In boys, the intake of sugary products increased from $17 \mathrm{~g}$ in 1985 to $27 \mathrm{~g}$ in 1995 but decreased to $20 \mathrm{~g}$ in 2007. Girls' intake increased from $11 \mathrm{~g}$ in 1985 to $26 \mathrm{~g}$ in 1995 but decreased to $20 \mathrm{~g}$ in 2007. For boys, intake of non-alcoholic beverages (including fruit and vegetable juices, cordials, tea and coffee, mineral waters, electrolyte drinks, sugar and non-nutritively sweetened soft drinks) increased from $490 \mathrm{~g}$ to $724 \mathrm{~g}$ to $1555 \mathrm{~g}$ across 1985, 1995 and 2007. For girls, intake of non-alcoholic beverages (non-nutritively sweetened varieties) increased from $459 \mathrm{~g}$ to $592 \mathrm{~g}$ to $1342 \mathrm{~g}$ across 1985 , 1995 and 2007. 
Figure 4. $24 \mathrm{~h}$ mean intake (g) of total sugars, sugary products, confectionery and non-alcoholic beverages * by Australian children in 1985, 1995 and 2007 [5,19]. Note: the age categories used for comparison where 10-15 year old children in years 1985 and 1995, the 2007 figure is an average between intakes of 9-13 year and 14-16 year categories.

TOTAL SUGARS (ADDED \& NATURALLY OCCURING)

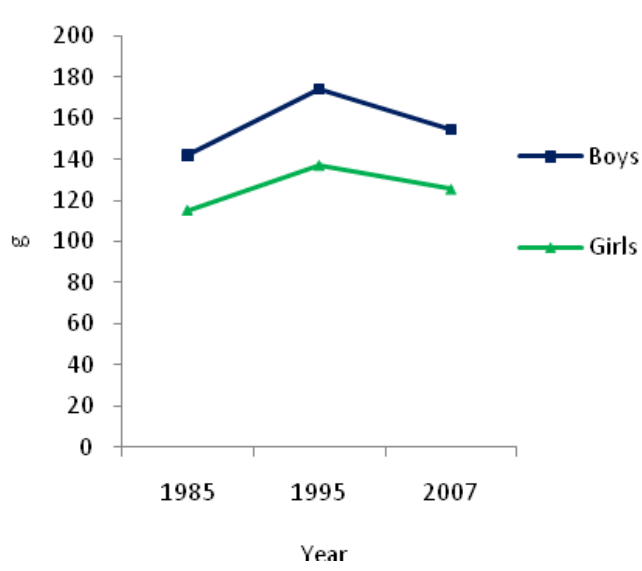

CONFECTIONERY

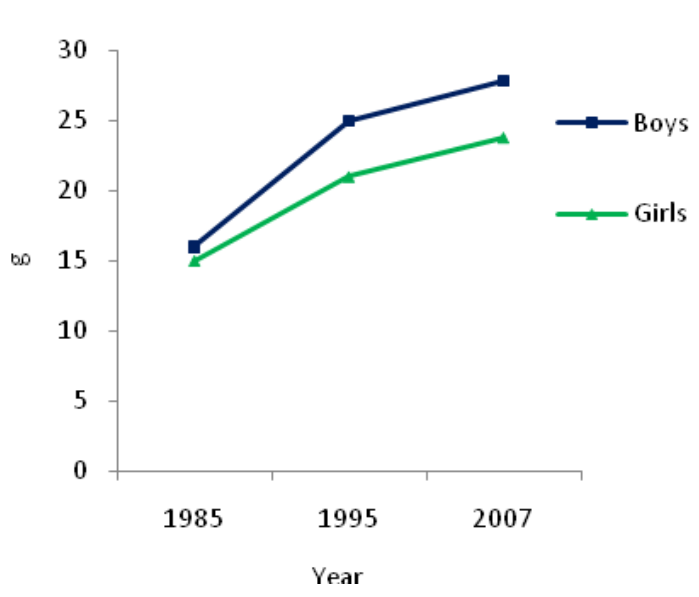

* Including coffee, tea and low joule soft drinks.
SUGARY PRODUCTS

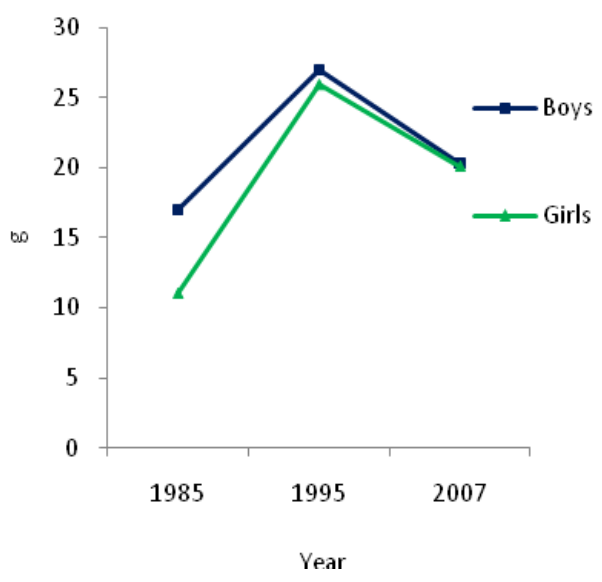

NON-ALCOHOLIC BEVERAGES

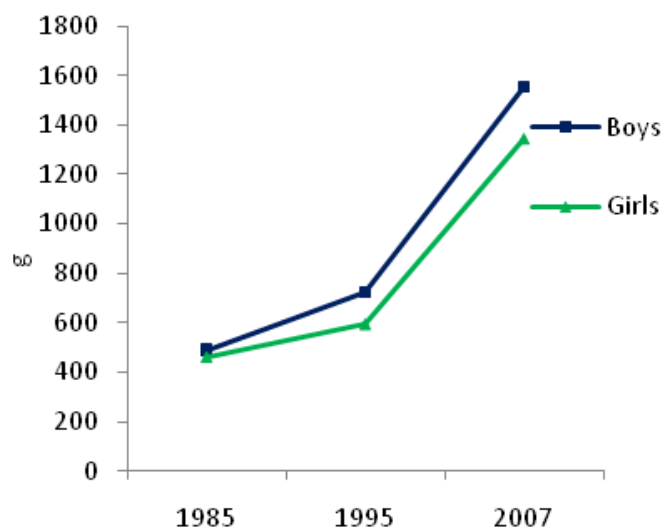

\subsection{Nutritively Sweetened Beverage Consumption from Sales Data}

Figure 5 shows the time trend in sales of nutritively sweetened and non-nutritively sweetened beverages in Australian grocery stores, expressed as total volume per capita [15,28-30]. Nutritively sweetened beverages made up the largest share of total water-based beverage sales, but during the period 2002-2006 there was a downward trend, with an absolute reduction in sales of nutritively sweetened beverages by 64 million liters. For nutritively sweetened beverages, sales were $96 \mathrm{~mL} /$ day/person in 1994, increasing to $129 \mathrm{~mL} /$ day/person in 2004, then decreasing to $125 \mathrm{~mL} /$ day/person in 2006. The sales of non-nutritively sweetened (diet/low-joule) beverages increased by 34\% from 1997 to 2006 [30]. Per capita, non-nutritively sweetened beverages sales doubled from $41 \mathrm{~mL} /$ day/person in 1994 to $82 \mathrm{~mL} /$ day/person in 2006 [15,28]. 
Figure 5. Time trends in sales of nutritively sweetened beverages and non-nutritively sweetened beverages in grocery stores, expressed as (A) per capita volume sold in liters and as (B) a percentage of total volume sold [15,28-30].

(A)

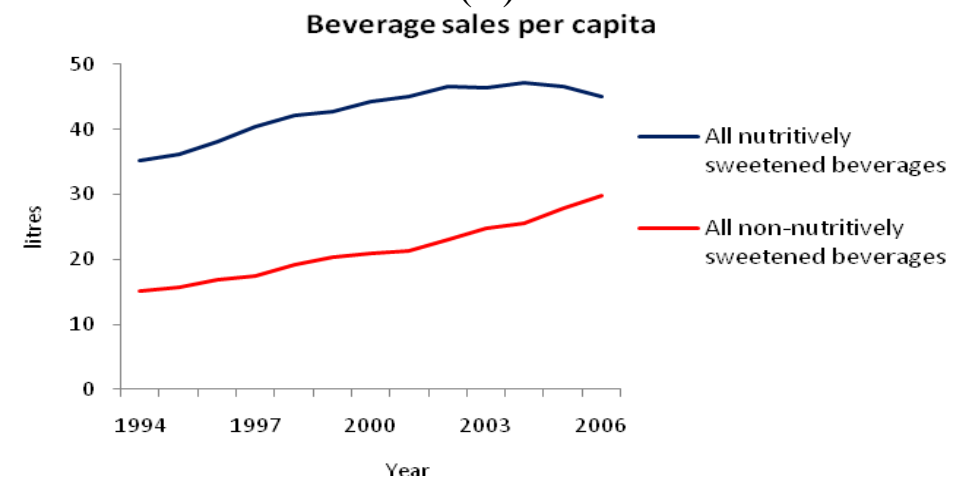

(B)

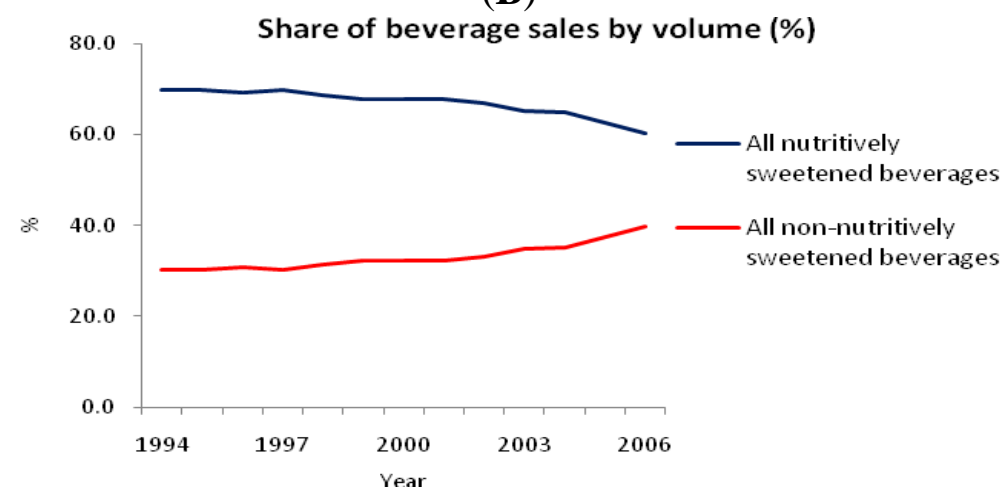

Figure 6 shows the annual change in the contribution of sugar from nutritively sweetened carbonated soft drinks (sugar-sweetened soft drinks) to the Australian food supply [30]. Levy and Tapsell [30] reported a concurrent increase in sugar from other nutritively sweetened beverages (e.g., sports drinks, flavored waters and iced teas). However, the increase in sugar contribution to the food supply from these beverages did not contribute enough volume to match the decline in nutritively sweetened carbonated soft drinks. Overall, there was a decrease in sugar contribution from nutritively sweetened carbonated soft drinks to the Australian food supply, amounting to 12,402 tons ( 600 g per person per year, Figure 6) from 2002 to 2006.

Figure 6. Annual change in contribution of nutritively-sweetened carbonated soft drinks to total added sugar in the Australian food supply [30].

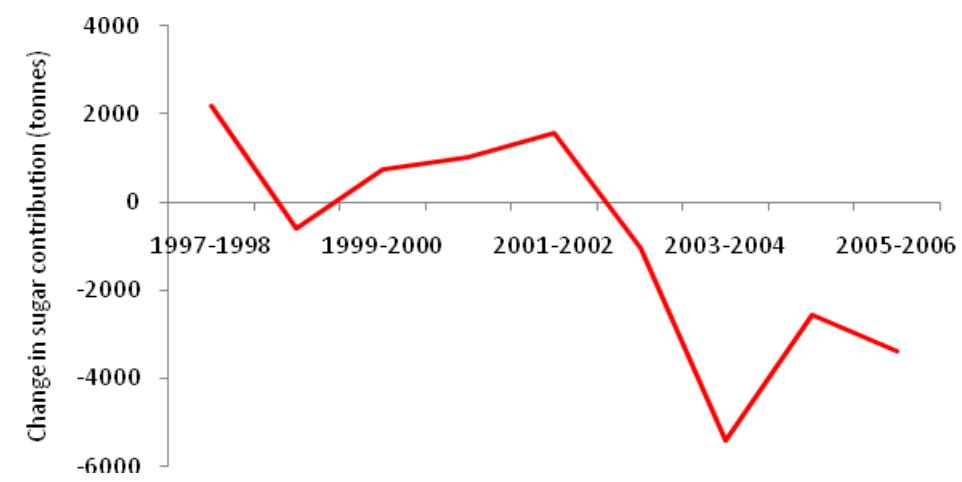




\subsection{Consumption of Soft Drinks, Flavored Waters, Electrolyte Drinks and Fruit Juice by Children}

Overall, the percentage of children who consumed soft drinks, flavored waters and electrolyte drinks (both sugar and non-nutritively sweetened) declined from the 1995 NNS to the 2007 Australian National Children's Nutrition and Physical Activity Survey [5,26] (Figure 7A). Among consumers, mean and median intakes of soft drinks, flavored waters and electrolyte drinks also decreased (Figure 7B). In the 16-18 year age group, mean intake fell by $33 \%$ to $278 \mathrm{~g}$. In the $12-15$ year age group, mean intake fell by $6 \%$ to $247 \mathrm{~g}$ in 2007 . In the $8-11$ year age group mean intake fell by $10 \%$. In the 4-7 year age group mean intake fell by $45 \%$. For the 2-3 year age group, mean intake fell by $55 \%$ to $26 \mathrm{~g}$ in 2007.

Figure 7. (A) Percent consuming, (B) mean intakes and (C) median intakes of soft drinks, flavored waters and electrolyte drinks by children in 1995 and 2007, and (D) percentage of energy supplied by fruit juice in the diets of children $[5,26]$.

(A)

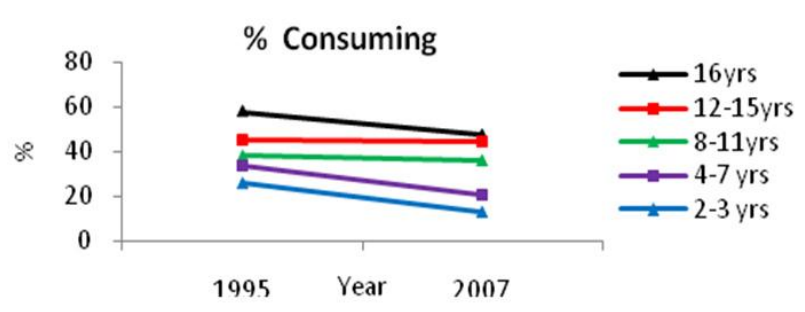

(C)

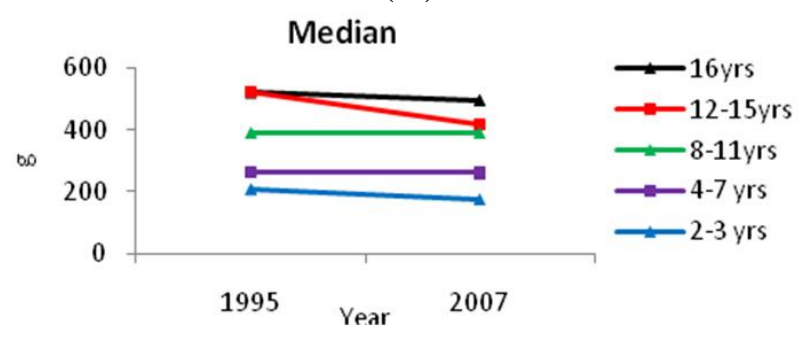

(B)

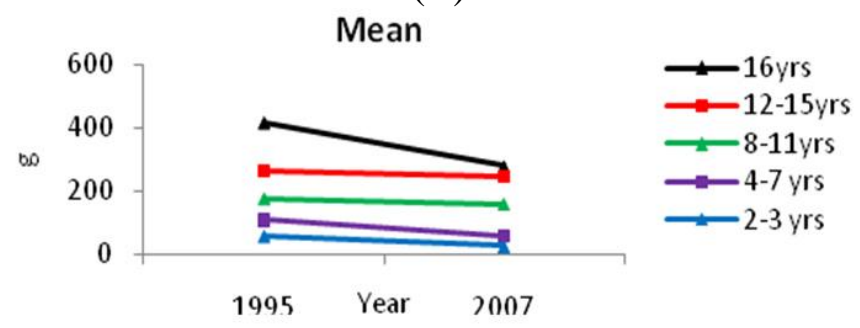

(D)

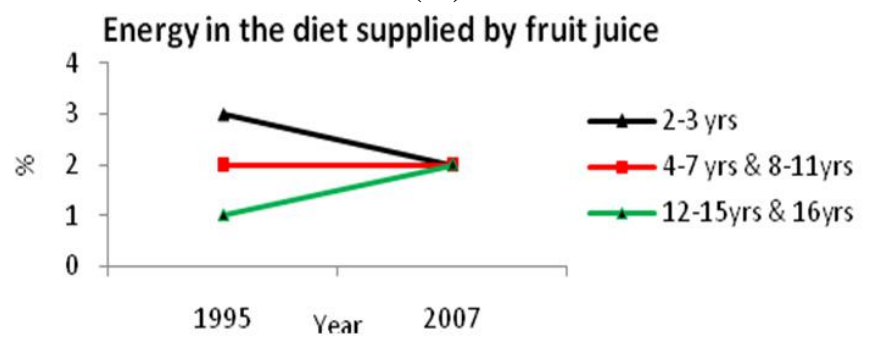

Similarly, median intake (in grams) of soft drinks, flavored waters and electrolyte drinks decreased across all age groups apart from the 8-11 year group which remained static at $391 \mathrm{~g} /$ day.

Fruit juice consumption is also of interest because, like soft drinks, they represent sugars in an acidic solution. The percentage of energy supplied by fruit juice was small (of the order of 1-3\% depending on age group) and changes between 1995 and 2007 were small.

\section{Discussion}

This analysis of apparent consumption, national dietary surveys and food industry data indicates a consistent and substantial decline in total refined or added sugar consumption by Australians over the past 30 years. In this respect, Australia may be unique, although FAO statistics suggest a modest reduction in refined sugar intake has also occurred in the UK. These trends contrast with a sizeable increase in the intake of total nutritive sweeteners in the USA, attributable to increased intake of high 
fructose corn syrup. Notably, Australia is a major grower and exporter of sugar cane, and the majority of nutritive sweetener use is in the form of refined sucrose [31].

Over the same timeframe, like other developed nations, Australia has experienced a 3-fold increase in the prevalence of obesity among adults and children. Hence in this ecological analysis, trends in refined sugar consumption are inversely related to incremental weight gain in the population as a whole. These findings support the supposition that once total energy intake has been accounted for, per capita changes in energy from sweeteners do not explain changes in the incidence of obesity [32]. Studies using individual dietary intakes have also reported inverse associations between sugar intake and body weight $[33,34]$. In Australia, two independent analyses of the most recent National Nutrition Survey reported no significant associations between intakes of sugars and health status, including body fatness, BMI and blood pressure [35,36]. Finally, while Australia already has some of the highest rates of overweight/obesity in the world [4,5], we are unable to rule out the possibility that rates may have be higher if consumption of sugars had not decreased over the past few decades.

Our findings suggest that Australians have taken seriously public health recommendations to decrease sugars, particularly sugar-sweetened beverages. Food industry data indicate that per capita sales of low calorie (non-nutritively sweetened) beverages doubled from 1994 to 2006 while nutritively sweetened beverages decreased by $10 \%$. At present, one in three soft drinks sold in Australia are non-nutritive [15,28-30]. Indeed, Australians have willingly adopted many other public health recommendations, including universal wearing of seat belts (the "click clack, front and back" campaign) and sunscreens (the "slip, slop, slap" campaign).

Evidence for an association between sugars consumption and weight gain from clinical trials and epidemiological studies has been inconclusive. There have been four systematic reviews that have included evidence from a large range of clinical trials, cohort studies and cross-sectional analyses, that have investigated the role of sugar sweetened beverages in the development of obesity in humans aged 1-99 years [8,37-39]. Of these, only one [8] supported an independent role for sugar sweetened beverages in the etiology of overweight/obesity. Similarly, there have been two systematic reviews investigating the role of added sugars in the development of obesity in men and women [40,41]. When sucrose, glucose, or starch was replaced with $>100 \mathrm{~g}$ of fructose/day, a weight gain of $0.44 \mathrm{~kg} / \mathrm{week}$ was observed in adults [40], whereas there were inconsistent associations when sugars were replaced with non-nutritive sweeteners, starch and fat [41]. Larger, well designed clinical trials are needed to further investigate this relationship.

A limitation common to all ecological studies is that relationships observed for groups do not necessarily hold for individuals. In the national population surveys, the dietary methodologies employed varied from food frequency questionnaires to $24 \mathrm{~h}$ recall of food intake. Recall data are only a crude estimate of actual intake, especially in children where there is high day-to-day variability. For adults, the most recent nationally representative food intake data are now 15 years old. Recall precision accuracy, low response rates, reporting and classification errors were relatively common and may have introduced confounding. Per capita consumption data are useful in determining upward or downward trends over time and for filling gaps by describing current levels of sugar intake for the entire population. Like all apparent consumption data, there are limitations in describing individual intake due to losses that occur when foods are actually prepared and consumed (e.g., plate wastage). Indeed, Baghurst and colleagues found that intake data from several population surveys indicated that the 
mean level of consumption of refined sugars was not as high as was estimated from apparent consumption [42]. Nonetheless, in the case of refined sugar, individuals may consciously or unconsciously underestimate intake of a substance that is considered unhealthy. Because refined sugar is a highly controlled commodity that is not grown for personal use, apparent consumption data are perhaps the most objective way to assess trends over time. Per capita food consumption statistics from FAO have compared favorably with energy and macronutrient intake estimated from population surveys [32,43].

Finally, data generated by the food and beverage industry for its own purposes may not be entirely reliable because there is no independent monitoring or peer review. However, industry makes financial decisions based on consumer demand and buying patterns and there is no reason to believe that it does not reflect the true state of affairs. Their data provide information on product usage that, combined with direct intake data, provide useful insights into the food environment.

Our findings do not support the widely held belief that reducing the consumption of refined sugars, and increasing the availability and preference for low-joule beverages, will help to reverse societal trends in obesity. Most recently, the American Heart Association stated that "added sugars are an important factor in the obesity crisis" and set strict guidelines for added sugar intake [44]. Specifically the guidelines recommend that Americans should eat or drink no more than 5 teaspoons $(25 \mathrm{~g})$ of added sugar per day for most women and 9 teaspoons $(45 \mathrm{~g}$ ) per day for the majority of men.

Clearly, overconsumption of energy relative to needs must be addressed to halt the obesity epidemic. However, a recent analysis of Australian children's dietary intakes from 1995 to 2007 revealed a substantial decrease in sugar-sweetened beverage (halved as a percentage of energy) consumption over the past decade, but increased consumption in the proportion of energy from chocolate, cakes and cookies, pizza and packet chips [33]. Furthermore, the 2007 National Children's Nutrition and Physical Activity Survey showed that sugar and sugary beverages were not predominant "extra" foods in the diets of Australian children. Therefore, the question of whether there is much to be gained by focusing public health policy on the removal of sugar and sugar-sweetened beverages remains. The concern is that potentially more important determinants of obesity are being overlooked by the current emphasis on sugars and soft drinks.

Questioning the priority of public health messages is relevant. It is possible that less emphasis has been given to disseminating the message of lowering total energy intake, while avoidance of particular nutrients, such as sugars, has been the primary focus. In practice, many individuals over-consume "fast" foods along with a diet drink. Interestingly, research by WHO found that the Australian energy supply has increased almost exclusively as a result of an increase in intake of fat [32]. Likewise, strategies aimed at reduction of added sugars consumption alone will not automatically improve overall dietary quality [45]. Indeed, lower relative fat consumption was obvious in the high added sugars consumers (the sugar fat seesaw), which would suggest that a reduction in added sugars might lead to increased fat consumption. Logic tells us that an inappropriately high intake of any energy source (alcohol, fat, protein, starch or sugar) will result in weight gain.

Indeed, a literal interpretation of our findings would suggest that reductions in sugar intake may have contributed to the rise in obesity. Lowering the sugar content of foods may be counterproductive for weight management if there is replacement of sugars with refined or high glycemic index starches, saturated fats or alcohol. 


\section{Conclusions}

The present analysis indicates the existence of an Australian Paradox, i.e., an inverse relationship between secular trends in the prevalence of obesity prevalence (increasing by $\sim 300 \%$ ) and the consumption of refined sugar over the same time frame (declining by $\sim 20 \%$ ). The findings challenge the implicit assumption that taxes and other measures to reduce intake of soft drinks will be an effective strategy in global efforts to reduce obesity.

\section{Acknowledgements}

This study was a Masters of Nutrition and Dietetic project conducted by Laura Owens and co-supervised by AWB and JBM.

AWB is a co-author of one of the books in The New Glucose Revolution book series (Hodder and Stoughton, London, UK; Marlowe and Co., New York, NY, USA; Hodder Headline, Sydney, Australia and elsewhere): Diabetes and Pre-diabetes handbook, and is a consultant to a not-for-profit GI-based food endorsement program in Australia.

JBM is a co-author of The New Glucose Revolution book series (Hodder and Stoughton, London, UK; Marlowe and Co., New York, NY, USA; Hodder Headline, Sydney, Australia and elsewhere), the Director of a not-for-profit GI-based food endorsement program in Australia and manages the University of Sydney GI testing service.

\section{References}

1. World Health Organization. Global Strategy on Diet, Physical Activity and Health; WHO: Geneva, Switzerland, 2004.

2. National Heart, Lung, and Blood Institute. Clinical Guidelines on the Identification, Evaluation, and Treatment of Overweight and Obesity in Adults: The Evidence Report; NHLBI: Bethesda, MD, USA, 1998.

3. World Health Organization. Consultation on Obesity; WHO: Geneva, Switzerland, 1999.

4. Australian Bureau of Statistics. 4364.0-National Health Survey: Summary of Results, 2007-2008; ABS: Canberra, Australia, 2009.

5. Commonwealth Scientific Industrial Research Organisation (CSIRO), Preventative Health National Research Flagship, the University of South Australia. 2007 Australian National Children's Nutrition and Physical Activity Survey-Main Findings; CSIRO: Clayton South, Australia, 2008.

6. Access Economics. The Growing Cost of Obesity in 2008: Three Years on; Diabetes Australia: Canberra, Australia, 2010.

7. Gross, L.S.; Li, L.; Ford, E.S.; Liu, S. Increased consumption of refined carbohydrates and the epidemic of type 2 diabetes in the United States: An ecologic assessment. Am. J. Clin. Nutr. 2004, 79, 774-779.

8. Malik, V.S.; Schulze, M.B.; Hu, F.B. Intake of sugar-sweetened beverages and weight gain: A systematic review. Am. J. Clin. Nutr. 2006, 84, 274-288.

9. World Health Organization, United Nations, 2009. Available online: http://www.who.int/en/ (accessed on 1 September 2009). 
10. Australian Bureau of Statistics, Commonwealth of Australia, 2009. Available online: http://www.abs.gov.au/ (accessed on 1 September 2009).

11. Australian Food and Grocery Council, 2009. Available online: http://www.afgc.org.au/ (accessed on 1 September 2009).

12. Australian Retailers Association, 2009. Available online: http://www.retail.org.au/ (accessed on 1 September 2009).

13. Commonwealth Scientific and Industrial Research Organization, Commonweath of Australia, 2009. Available online: http://www.csiro.au/ (accessed on 1 September 2009).

14. Australian Government, Commonweath of Australia, 2009. Available online: http://australia.gov.au/ (accessed on 1 September 2009).

15. Australian Beverages Council Ltd., 2009. Available online: http://www.australianbeverages.org/ home.html (accessed on 1 September 2009).

16. CSR Ltd., 2009. Available online: http://www.csr.com.au (accessed on 1 September 2009)

17. Wesfarmers Coles Supermarkets, 2009. Available online: http://www.coles.com.au/ (accessed on 1 September 2009).

18. Woolworths Ltd., 2009. Available online: http://www.woolworthslimited.com.au (accessed on 1 September 2009).

19. Cook, P.; Rutishauser, I.H.E.; Allsopp, R. The Bridging Study-Comparing Results from the 1983, 1985 and 1995 Australian National Nutrition Surveys; Commonwealth Department of Health and Aged Care: Canberra, Australia, 2001.

20. McLennan, W.; Podger, A. National Nutrition Survey Nutrient Intakes and Physical Measurements, Australia, 1995; Catalouge No. 4805.0; Australian Bureau of Statistics: Canberra, Australia, 1998.

21. Cameron, A.J.; Welborn, T.A.; Zimmet, P.Z.; Dunstan, D.W.; Owen, N.; Salmon, J.; Dalton, M.; Jolley, D.; Shaw, J.E. Overweight and obesity in Australia: The 1999-2000 Australian diabetes, obesity and lifestyle study (AusDiab). Med. J. Aust. 2003, 178, 427-432.

22. Australian Bureau of Statistics. National Health Survey 2004-05; Commonwealth of Australia: Canberra, Australia, 2006.

23. The Health and Social Care Information Centre, UK. Health Survey for England 2007, Latest Trends, 2008. Available online: http://www.ic.nhs.uk/webfiles/publications/HSE07/Health\%20 Survey\%20for\%20England\%202007\%20Latest\%20Trends.pdf (accessed on 1 September 2009).

24. National Centre for Health Statistics. Third National Health and Nutrition Examination Survey (NHANES III) Public-Use Data Files, 2004. Available online: http://www.cdc.gov/nchs/products/ elec_prods/subject/nhanes3.htm (accessed on 20 April 2006).

25. The Food and Agriculture Organization of the United Nations, Food consumption quantities, 2009. Available online: http://faostat.fao.org/site/368/DesktopDefault.aspx?PageID=368\#ancor (accessed on 11 August 2009).

26. Cobiac, L.; Mortensen, A.; Baghurst, K. The Role of Beverages in the Diet of Australian Children; Australian Beverages Council Ltd.: Rosebery, Australia, 2010.

27. Australian Bureau of Statistics. Census of population and housing, 2009. Available online: http://www.abs.gov.au/websitedbs/D3310114.nsf/Home/Census (accessed on 11 August 2009). 
28. Levy, G. Food Logic, 2009. Available online: http://www.foodlogic.com.au/ (accessed on 14 August 2009).

29. AC Nielsen ScanTrack, 2009. Available online: http://au.nielsen.com/products/crs_scantrack. shtml (accessed on 14 August 2009).

30. Levy, G.; Tapsell, L. Shifts in purchasing patterns of non-alcoholic, water-based beverages in Australia, 1997-2006. Nutr. Diet. 2007, 64, 268-279.

31. National Health and Medical Research Council. Dietary Guidelines for Children and Adolescents in Australia; Commonwealth of Australia: Canberra, Australia, 2003.

32. Silventoinen, K.; Sans, S.; Tolonen, H.; Monterde, D.; Kuulasmaa, K.; Kesteloot, H.; Tuomilehto, J. Trends in obesity and energy supply in the WHO MONICA Project. Int. J. Obes. Relat. Metab. Disord. 2004, 28, 710-718.

33. Gibney, M.; Sigman-Grant, M.; Stanton, J.L., Jr.; Keast, D.R. Consumption of sugars. Am. J. Clin. Nutr. 1995, 62, 178S-193S.

34. Hill, J.O.; Prentice, A.M. Sugar and body weight regulation. Am. J. Clin. Nutr. 1995, 62, 264S-273S.

35. Cobiac, L. Sugars in the Australian diet: Results from the 1995 National Nutrition Survey. Nutr. Diet. 2003, 60, 152-173.

36. Bell, A.C. Contribution of "noncore" foods and beverages to the energy intake and weight status of Australian children. Eur. J. Clin. Nutr. 2005, 59, 639-645.

37. Forshee, R.A.; Anderson, P.A.; Storey, M.L. Sugar-sweetened beverages and body mass index in children and adolescents: A meta-analysis. Am. J. Clin. Nutr. 2008, 87, 1662-1671.

38. Gibson, S. Sugar-sweetened soft drinks and obesity: A systematic review of the evidence from observational studies and interventions. Nutr. Res. Rev. 2008, 21, 134-147.

39. Wolff, E.; Dansinger, M.L. Soft drinks and weight gain: How strong is the link? Medscape J. Med. 2008, 10, 189.

40. Livesey, G.; Taylor, R. Fructose consumption and consequences for glycation, plasma triacylglycerol, and body weight: Meta-analyses and meta-regression models of intervention studies. Am. J. Clin. Nutr. 2008, 88, 1419-1437.

41. Vermunt, S.H.; Pasman, W.J.; Schaafsma, G.; Kardinaal, A.F. Effects of sugar intake on body weight: A review. Obes. Rev. 2003, 4, 91-99.

42. Baghurst, K.I.; Record, S.J.; Syrette, J.A.; Crawford, D.A.; Baghurst, P.A. Intakes and sources of a range of dietary sugars in various Australian populations. Med. J. Aust. 1989, 151, 512-518.

43. Sasaki, S.; Kesteloot, H. Value of food and agriculture organization data on food-balance sheets as a data source for dietary fat intake in epidemiologic studies. Am. J. Clin. Nutr. 1992, 56, 716-723.

44. Johnson, R.K.; Appel, L.J.; Brands, M.; Howard, B.V.; Lefevre, M.; Lustig, R.H.; Sacks, F.; Steffen, L.M.; Wylie-Rosett, J. Dietary sugars intake and cardiovascular health: A scientific statement from the American Heart Association. Circulation 2009, 120, 1011-1020.

45. Baghurst, K.I. Demographic and nutritional profiles of people consuming varying levels of added sugars. Nutr. Res. 1992, 12, 1455-1465.

(C) 2011 by the authors; licensee MDPI, Basel, Switzerland. This article is an open access article distributed under the terms and conditions of the Creative Commons Attribution license (http://creativecommons.org/licenses/by/3.0/). 